\title{
A EXPERIÊNCIA DO PROGRAMA ESPECIAL DE TREINAMENTO NA EDUCAÇÃO DE ESTUDANTES DE GRADUAÇÃO EM ENFERMAGEM
}

\author{
Silvia Helena De Bortoli Cassiani* \\ Waleska Zafred Ricci** \\ Carla Regina de Souza**
}

CASSIANI, S.H.D.B.; RICCI, W.Z.; SOUZA, C.R.de. A experiência do programa especial de treinamento na educação de estudantes de graduação em enfermagem. Rev.latino-am.enfermagem, Ribeirão Preto, v. 6, n. 1, p. 63-69, janeiro 1998.

O estudo apresentou o Programa Especial de Treinamento (PET), financiado pela Coordenação de Aperfeiçoamento de Pessoal de Ensino Superior (CAPES), em funcionamento desde 1989 na Escola de Enfermagem de Ribeirão Preto - USP e destinado a um grupo de doze estudantes com potencial, habilidades e interesse no curso de graduação. O programa propicia a orientação de um tutor, condições para executar atividades extra-curriculares e desenvolvimento de estudos relacionados a graduação. As atividades desenvolvidas são: curso de língua estrangeira, reuniões semanais com o tutor, trabalho científico sob a orientação de um professor, discussão de temas científicos e participação em eventos. Os estudantes agem como multiplicadores, disseminando idéias e práticas a outros estudantes. O PET tem excelente conceito na área acadêmica e alguns ex-alunos estão envolvidos em programas de pós-graduação. Segundo os bolsistas, o programa contribui para seu crescimento pessoal e profissional através da promoção de atividades que levam à integração da formação acadêmica e da futura atividade profissional.

UNITERMOS: alunos de graduação, iniciação científica

\section{INTRODUÇÃO}

Em enfermagem, há um consenso de formar profissionalmente indivíduos que atuarão de forma global no mercado de trabalho, transformando, inovando e lutando pelos interesses profissionais e da classe.

Para tanto, a grade curricular do curso de graduação apresenta várias disciplinas nas quatro áreas temáticas: Bases Biológicas e Sociais - incluindo conteúdos fundamentais das Ciências Biológicas e Humanas; Fundamentos de Enfermagem - incluindo os conteúdos técnicos, metodológicos e os meios e instrumentos inerentes ao trabalho do enfermeiro e da equipe de enfermagem em nível individual e coletivo; Assistência de Enfermagem com os conteúdos que compõem a assistência de enfermagem em nível individual e coletivo prestado à criança, ao adolescente e ao adulto, e a última área temática - Administração em Enfermagem com os conteúdos de administração do processo de trabalho da enfermagem e da assistência de enfermagem (BRASIL, 1994).
Entretanto, embora haja alguns avanços na estrutura curricular das escolas, persiste a fragmentação de conteúdos em pequenas disciplinas o que dificulta a visão global da articulação desses conteúdos na grade curricular e nas atividades práticas (ANGERAMI et al., 1994).

Além disto, importa também afirmar que disciplinas concentram elevada carga horária intra-sala de aula com a cobrança de trabalhos grupais e/ou individuais, preparação de estudos de caso, seminários, etc.. ocasionando por parte de alunos e docentes queixas de falta de espaço para estudos, leituras, participação em eventos, etc.

ANGERAMI et al. (1994) ainda afirmaram que, embora as escolas pretendam preparar um profissional que seja líder, criativo e engajado, não se oferece outras oportunidades de aprendizagem ao aluno.

Nesse sentido, é mister encorajar atitudes que ofereçam aos discentes oportunidades para a prática de atividades extra-curriculares em consonância com as disciplinas cursadas e os conhecimentos já obtidos.

\footnotetext{
* Enfermeira. Professora Doutora do Departamento de Enfermagem Geral e Especializada. Tutora do Programa Especial de Treinamento (PET) na Escola de Enfermagem de Ribeirão Preto da Universidade de São Paulo desde 1994

** Enfermeiras. Bolsistas do Programa Especial de Treinamento (PET) na Escola de Enfermagem de Ribeirão Preto da Universidade de São Paulo de março de 1993 a março de 1996
} 
Uma atividade que tem se destacado e motivado os alunos no curso de graduação é a participação destes em pesquisas científicas conduzidas em colaboração com os docentes. Para tanto, recebem auxílio financeiro de vários órgãos governamentais brasileiros, sob a forma de bolsas de iniciação científica. Tais bolsas visam proporcionar ao aluno a aprendizagem de métodos científicos, induzindo o questionamento crítico e o espirito científico.

Esta colaboração docente-discente na execução de um projeto científico tem as finalidades de contribuir para a formação de uma concepção científica do mundo; reforçar a formação do interesse e da inclinação permanente ao conhecimento e ao desenvolvimento de habilidades e hábitos; contribuir para a aquisição de métodos de trabalho científico e a utilização dos mesmos na solução de tarefas; contribuir para a aquisição de conhecimentos, criar hábitos na busca de informação, organização e a utilização crítica do mesmo e contribuir para estreitar as relações de estudantes e docentes vinculados em um trabalho comum (AMADOR et al., 1984).

Todavia, embora os objetivos da iniciação científica sejam focalizados no desenvolvimento de conhecimentos, verifica-se no cotidiano alguns pontos intervenientes e limitações como a utilização do aluno como mera mão-de-obra para coletar dados sem uma participação efetiva na investigação.

Outra modalidade de investimento tem sido o Programa Especial de Treinamento (PET) que, por não ser considerado uma bolsa de iniciação científica nos moldes das já citadas, merece destaque neste estudo, visto ser uma das únicas programações que financia alunos com potencial, propicia-lhes condições para a realização de atividades extra-curriculares que favorecem a sua formação acadêmica, a sua integração no mercado profissional e o desenvolvimento de estudos em programas de pós-graduação.

Pretendemos, desta forma, descrevê-lo, particularizando o caso da EERP-USP, a fim de torná-lo mais visível e conhecido nas escolas de enfermagem no Brasil e até no exterior.

\section{OBJETIVO}

O objetivo deste estudo é apresentar o PET enfocando as características, atividades programadas, situação atual, a avaliação obtida pela CAPES e os resultados alcançados por este grupo nos anos de $1994 \mathrm{e}$ 1995 na EERP-USP.

\section{DESENVOLVIMENTO DO PET}

O PET é integrado por grupos tutoriais de aprendizagem e busca propiciar aos alunos, sob a orientação de um professor tutor, o desenvolvimento de conhecimentos através das várias atividades programadas. Foi idealizado em finais da década de 70, pelo Prof ${ }^{\circ}$ Cláudio de Moura Castro, ex-diretor geral da CAPEs Coordenadoria de Aperfeiçoamento de Pessoal de Nível Superior, a partir de experiências na Faculdade de Ciências Econômicas (FACE) da Universidade Federal de Minas Gerais e nos Honors Programs oferecidos em algumas universidades americanas.

A meta dos programas "honors students", que se mantém até os dias de hoje é de auxiliar os estudantes a desenvolverem métodos de pensamento e conhecimento intelectual através da pesquisa.

BURKHALTER \& TIM (1976) da University of Hawaii em Manoa - Honolulu descreveram os benefícios deste programa e cujas características apresentam relações muito semelhantes às do PET como: experiência no processo de pesquisa servindo como um início de investigação na pós-graduação, ambiente estimulante e desafiador para a aprendizagem geral e participação em colóquios e cursos multidisciplinares.

Desta forma o P.E.T. passou por várias fases desde sua criação, mantendo o objetivo de formar profissionais de alto nível para todos os segmentos do mercado de trabalho, com destaque para a carreira universitária e a pós-graduação.

Atualmente, o PET constitui-se em uma modalidade de investimento acadêmico em cursos de graduação e têm sérios compromissos epistemológicos, pedagógicos, éticos e sociais. Os objetivos do programa são:

- oferecer uma formação acadêmica de excelente nível, visando a formação de um profissional crítico e atuante, através da facilitação do domínio dos processos e métodos gerais e específicos de investigação, análise e atuação da área de conhecimento; envolvimento dos bolsistas em tarefas e atividades que propiciem o aprender fazendo; discussão de temas éticos, sócio-políticos, científicos e culturais para o país e/ou para o exercício profissional. - promover a integração da formação acadêmica com a futura atividade profissional, especialmente no caso da carreira universitária, através da interação constante entre as atividades de ensino, pesquisa e extensão.

- estimular a melhoria do ensino de graduação através de desenvolvimento de novas práticas e experiências pedagógicas; atuação dos bolsistas como agentes multiplicadores; interação dos bolsistas com os corpos docente e discente da instituição e participação em atividades características de programas de PósGraduação. 
Com base nesses objetivos, as características básicas do PET são: a formação acadêmica ampla, interdisciplinaridade, atuação coletiva, interação contínua e planejamento e execução de um programa diversificado de atividades.

Não é pois objetivo formar somente pesquisadores a partir do envolvimento de alunos de graduação em projetos de pesquisa de docentes tal como é característica de programas de bolsas de iniciação científica; também difere de programas de estágio que tem como objetivo promover oportunidades de aplicação prática dos conhecimentos teóricos adquiridos no curso de graduação. Não pode-se defini-lo, portanto, como um programa de iniciação científica.

\section{METODOLOGIA DO PROGRAMA}

\section{Método tutorial}

A concepção do programa está baseada nos moldes de grupos tutoriais de aprendizagem e orientado pelo objetivo de formar globalmente o aluno.

O grupo tutorial se caracteriza pela presença de um tutor com a missão de estimular a aprendizagem ativa dos seus membros através de vivências, reflexões e discussões num clima de informalidade e cooperação. $\mathrm{O}$ método tutorial permite o desenvolvimento de habilidades de resolução de problemas e pensamento crítico entre os bolsistas. É definido por Bligh apud ASHTON \& SHULDMAM ( 1994 ) como uma situação em que um pequeno grupo de alunos encontra-se com um tutor para discussão.

Nos grupos PET, o tutor é o responsável pelo planejamento das atividades bem como pelo desempenho do grupo sob sua orientação, contando com a colaboração de outros docentes para o desenvolvimento de suas ações.

O tutor deve ter, no mínimo, a titulação de doutor, pertencer ao quadro permanente em regime de tempo integral, comprometer-se a dedicar uma carga horária semanal mínima de oito horas às atividades do grupo, comprometer-se à assumir a tutoria por um prazo mínimo de três anos e adequar-se a um perfil que inclua: vida acadêmica destacada, experiência na orientação de alunos; visão ampliada do curso de Graduação; desenvolvimento de atividades ligadas à melhoria da qualidade de ensino do curso; bom relacionamento com os corpos docente e discente e identificação com a filosofia e os objetivos do PET.

\section{Grupos em funcionamento}

Atualmente, no Brasil, duzentos e cinqüenta e sete (257) grupos estão em funcionamento sendo divididos por área conforme segue:

Quadro 1: Número de grupos PET em funcionamento por área*

\begin{tabular}{|l|c|}
\hline \multicolumn{1}{|c|}{ Área } & Número \\
\hline Ciências exatas e da terra & 50 \\
\hline Ciências Biológicas & 17 \\
\hline Engenharias & 39 \\
\hline Ciências da Saúde & 34 \\
\hline Ciências Agrárias & 29 \\
\hline Ciências Sociais Aplicadas & 35 \\
\hline Ciências Humanas & 42 \\
\hline Lingüistica, Letras e Artes & 11 \\
\hline Total & 257 \\
\hline
\end{tabular}

* Fonte: DESSEN, M.A. O programa especial de treinamento - PET: evolução e perspectivas futuras. 1995 (Mimeografado)

Deste total cinco (05) são grupos da Enfermagem, sendo três (03) localizados na região Nordeste e dois (02) na região sudeste, um destes em Ribeirão Preto.

\section{O grupo em particular}

O grupo PET constitui-se fundamentalmente por um micro grupo composto por doze membros, liderados por um tutor com os objetivos de desenvolvimento de trabalhos científicos, crescimento pessoal e intelectual do aluno, exercício de atividades planejadas em grupos e integração com docentes e discentes, caracterizando-se portanto um grupo tutorial.

Sabe-se que vários fatores influenciam o dinamismo do grupo. O fato do grupo ser renovado anualmente com a substituição de alunos graduados por outros, através de um processo seletivo, torna a formação deste grupo pouca espontânea, com inter-relações que podem ser mais fracas e menos construtivas. Os alunos ingressantes tem-se mostrado, logo no primeiro ano, mais passivos, esperando do tutor iniciativas, soluções de conflitos e participação nos trabalhos. Entretanto, tal posição tende a modificar-se quando a relação grupal é estabelecida e há confiança entre seus membros.

A contribuição de cada um dos membros, suas diferenças, o relacionamento grupal e o estilo de liderança adotado pela tutoria refletem na formação e funcionamento do grupo, que de maneira cíclica encorajam o tutor para um estilo ou outro.

Ao tutor exige-se flexibilidade para usar estilos diferentes, sem chegar a extremos de incongruência, atendendo ou não as expectativas individuais e grupais. A eficácia da liderança do tutor depende dos fatores 
situacionais, natureza da tarefa, a estrutura das recompensas da organização do grupo, o clima de organização, habilidades, personalidade, expectativas e experiências do tutor e dos membros do grupo.

O tutor exerce papel fundamental na condução do grupo, estabelecendo diretrizes, metas a serem alcançadas e manutenção do relacionamento grupal para a obtenção de resultados efetivos.

\section{O PET NA ESCOLA DE ENFERMAGEM DE RIBEIRÃO PRETO}

O Programa Especial de Treinamento - PET/ CAPES na EERP-USP, foi implantado em setembro de 1988, contando inicialmente com 04 bolsistas, ambas do $4^{\mathrm{o}}$ semestre de graduação.

Desde o início do Programa, dezessete (17) alunos já passaram pelo programa. Destes, três (03) estão envolvidos em projetos de pesquisa de docentes da Unidade, três (03) estão cursando a Pós-Graduação, nível Mestrado, uma (1) faz o Curso de Especialização em Enfermagem do trabalho e os demais atuam como enfermeiros em Instituições de Saúde.

Os alunos ingressam no programa através de um processo seletivo, e devem ter como requisitos: estar cursando o segundo ou terceiro semestre da graduação, ter a expectativa de permanecer como bolsista até a conclusão do seu curso de graduação, não apresentar reprovação no histórico escolar, ter apresentado um bom rendimento escolar nas disciplinas cursadas, ser brasileiro nato ou naturalizado, ter até 22 anos de idade à época do início da bolsa e comprometer-se a dedicar, no mínimo, 12 horas semanais às atividades do programa.
Após a aprovação no processo seletivo, os alunos ingressam no programa e permanecem neste até a conclusão do curso de graduação, recebendo auxílio financeiro mensal fixado pela CAPES. Espera-se que o bolsista mantenha bom rendimento no curso de graduação, apresente excelente rendimento acadêmico avaliado pelo professor tutor, participe ativamente das atividades especificas do grupo PET, dedique-se em tempo integral, às atividades do curso e do programa e não receba outro tipo de bolsa.

Os bolsistas são encorajados a realizar investigação, apresentá-las em eventos científicos e submetê-las à análise para publicação em revistas nacionais. $\mathrm{O}$ quadro na página seguinte indica os títulos dos projetos/investigações realizados pelos bolsistas nos anos de 1994 e 1995:

\section{Resultados para os bolsistas}

Os bolsistas no ano de 1995 visitaram sete instituições hospitalares de ponta no país que contaram com a participação de mais sessenta e quatro (64) alunos da unidade não bolsistas. Participaram, ainda, de cinco eventos em que apresentaram trabalhos científicos, assistiram vinte seminários/ congressos, doze filmes/ exposições. Foram ouvintes em dez congressos, participaram de dezenove cursos extra-curriculares e três em outras áreas. Seus trabalhos resultaram em vinte e três publicações em Anais ou Programas, juntos fizeram leituras e debates de quatro artigos, três teses e sete livros.

Sob o aspecto qualitativo, quando indagados qual a sua vivência e expectativa de ser um aluno PET, os bolsistas fizeram, em relatório, as seguintes declarações:

\section{QUADRO 2: Títulos, objetivos e situação dos projetos/investigações realizados pelos bolsistas}

\begin{tabular}{|c|c|c|}
\hline TÍTULO & OBJETIVOS & SIT UAÇÄO \\
\hline $\begin{array}{l}\text { A criança diabética, os pais e/ou } \\
\text { responsávelfrente à insulinoterapia }\end{array}$ & $\begin{array}{l}\text { Caracterizar a criança diabética tipo I ouinsulino-dependente } \\
\text { e a sua famulia e obter as informações que a criança, os pais } \\
\text { e/ou responsável têm em relação a insulinoterapia }\end{array}$ & Concluído \\
\hline $\begin{array}{l}\text { Caracterizando a atividade do } \\
\text { pesquisar na época de sua } \\
\text { introdução - a década de } 70- \\
\text { segundo depoimentos de } \\
\text { enfermeiras }\end{array}$ & $\begin{array}{l}\text { Reconstituir a evolução histórica da pesquisa em } \\
\text { enfermagerm, buscando o momento de sua inserção na } \\
\text { profissão; identificar os reflexos desta no ensino e na } \\
\text { assistência segundo a opiniãode enfermeiras e/oudocentes } \\
\text { que vivenciaram a época de introdução dos cursos de } \\
\text { mestrado }\end{array}$ & Concluido \\
\hline $\begin{array}{l}\text { A pesquis a científica sob a } \\
\text { perspectivado aluno de graduação } \\
\text { dos cursos de farmácia e } \\
\text { enfermagem }\end{array}$ & $\begin{array}{l}\text { Levantar nos livros de Metodologia Científica disponíveis } \\
\text { na biblioteca central do Campus da USP de Ribeirão Preto, } \\
\text { os conceitos e a finalidade atribuidos à pesquisa científica } \\
\text { pelos alunos dos cursos de graduação em farmácia e } \\
\text { enfermagem do Campus da USP de Ribeirão Preto }\end{array}$ & Concluido \\
\hline
\end{tabular}




\begin{tabular}{|c|c|c|}
\hline TÍTULO & OBJETIVOS & SITUACÃO \\
\hline O paradoxo sexo e adolescência & $\begin{array}{l}\text { Avaliar o grau de conhecimento do adolescente sobre } \\
\text { sexualidade; } \\
\text { levantar suas dúvidas e o seu relacionamento com os pais, } \\
\text { bem como a aceitação; } \\
\text { viabilizar a implantação de programas de educação sexual } \\
\text { nas escolas de } 1^{\circ} \text { grau de Ribeirão Preto }\end{array}$ & Concluído \\
\hline $\begin{array}{l}\text { A perspectiva dos enfermeiros em } \\
\text { serviços hospitalares. Sistemas de } \\
\text { Informação sobre nas cimentos: } \\
\text { revisão de literatura }\end{array}$ & $\begin{array}{l}\text { Conhecer o que os enfermeiros da área hospitalar } \\
\text { desenvolvem enquanto atividade de supervisão. Analisar as } \\
\text { publicações sobre o sistemade informações de nascimentos }\end{array}$ & Concluído \\
\hline $\begin{array}{l}\text { O enfermeiro na as sistência à } \\
\text { família }\end{array}$ & $\begin{array}{l}\text { Conhecer como é abordada, na liter atura profis sional, a } \\
\text { assistência de enfermagem à familia }\end{array}$ & Concluído \\
\hline $\begin{array}{l}\text { Medida da pressão arterial do } \\
\text { membro superior esquerdo e suas } \\
\text { alterações decorrentes das } \\
\text { diferentes posições, emhipertensos } \\
\text { leves }\end{array}$ & $\begin{array}{l}\text { Saber qual a alteração nos valores das pressões arteriais } \\
\text { sistólica e diastólica devido à mudança de posição, sentado } \\
\text { e de pé em hipertensos leves, com exclusão dos fatores de } \\
\text { interferência relacionados aos instrumento, pacientes e } \\
\text { observados }\end{array}$ & Em exe cução \\
\hline $\begin{array}{l}\text { O significado do "retomando a } \\
\text { falar" entre as pessoas } \\
\text { laringectomizadas }\end{array}$ & $\begin{array}{l}\text { Compreender o significado cultural do retomo da capacidade } \\
\text { de emissão da voz entre as pessoas laringectomizadas que } \\
\text { se comunicam com a voz esofágica }\end{array}$ & Em exe cução \\
\hline $\begin{array}{l}\text { Informalização da Administração } \\
\text { da Assistência de Enfermagem: - } \\
\text { expectativas dos alunos de } \\
\text { gradıação }\end{array}$ & $\begin{array}{l}\text { Verificar o nivel de conhecimentos do aluno de graduação } \\
\text { em enfermagem, na área de informátic a aplicada à } \\
\text { enfermagem; } \\
\text { conhecer as expectativas e a importância atribuída ao } \\
\text { computador na vida profissional }\end{array}$ & Em exe cução \\
\hline $\begin{array}{l}\text { Estudo do conhecimento e das } \\
\text { dificuldades de alunos do } 2^{\circ} \text { grau } \\
\text { de uma escola estadual de Ribeirão } \\
\text { Preto, relativos à sexualidade - } \\
\text { DST/AIDS }\end{array}$ & $\begin{array}{l}\text { Estudar o conhecimento e as dificuldades de alunos do } 2^{\circ} \\
\text { grau de uma Escola Estadual de Ribeirão Preto, em relação } \\
\text { à sexualidade e DST/AIDS }\end{array}$ & Concluído \\
\hline $\begin{array}{l}\text { Envolvimento do complexo } \\
\text { amigdalóide na ansiedade gerada } \\
\text { em ratos pela exposição ao } \\
\text { labirinto em cruz elevado }\end{array}$ & $\begin{array}{l}\text { Verificar o envolvimento do sistema GABA/BZA do } \\
\text { complexo amigdalóide na ansiedade gerada em ratos pela } \\
\text { exposição ao labirinto em cruz elevada }\end{array}$ & $\begin{array}{l}\text { Apresentado em eventos } \\
\text { científicos }\end{array}$ \\
\hline $\begin{array}{l}\text { Contribuição à operacionalização } \\
\text { da sistematização da assistência de } \\
\text { enfermagem }\end{array}$ & $\begin{array}{l}\text { Desenvolver um instrumento de coleta de dados alicerçado } \\
\text { no referencial da Teoria daNecessidades Humanas Básicas, } \\
\text { operacionalizável na realidade de trabalho de Clírica Médica }\end{array}$ & $\begin{array}{l}\text { Apresentado em eventos } \\
\text { científicos }\end{array}$ \\
\hline $\begin{array}{l}\text { A liderança exercida por } \\
\text { enfermeiros recém-formados }\end{array}$ & $\begin{array}{l}\text { Levantar junto a enfermeiros recém-formados seus } \\
\text { conhecimentos sobre a liderança em enfermagem, } \\
\text { percepções e a respeito de sua habilidade em liderança e a } \\
\text { contribuição da graduação para seu desempenho }\end{array}$ & $\begin{array}{l}\text { Apresentado em evento } \\
\text { científico }\end{array}$ \\
\hline $\begin{array}{l}\text { Uma experiência em educação em } \\
\text { serviço }\end{array}$ & $\begin{array}{l}\text { Propor a dis cuss ão do proces so de de sinfecção dos } \\
\text { nebulizadores com vistas a uma sensibilização do pessoal } \\
\text { de enfermagem }\end{array}$ & $\begin{array}{l}\text { Apresentado em evento } \\
\text { científico }\end{array}$ \\
\hline
\end{tabular}


"Ao ingressar-me no PET percebi que a Enfermagem é muito mais que simples cuidar, que fornece muitas oportunidades para o aluno se desenvolver dentro e fora do contexto universitário. Além disso, o desenvolvimento de uma investigação científica propicia mais uma experiência a nós. Ó único problema é que ultimamente era um órgão fechado de pouco acesso aos graduandos que não pertenciam a ele."

"Ter sido parte integrante do grupo PET significou para mim um grande crescimento pessoal e profissional. Através desse programa tive a oportunidade de familiarizar e descobrir uma parte do mundo da pesquisa, indispensável a qualquer profissional que não deseja se acomodar no cotidiano de suas atividades e à todo aquele que deseja ter as suas inquietações, se não resolvidas, acalmadas. O PET me proporcionou um crescimento pessoal muito importante, ensinando-me como conviver com o grupo, discutindo, respeitando, construindo com o outro, me ensinou a descobrir em mim mesma novos talentos, gostos e tendências em muitos aspectos, na arte, na música e literatura. Não poderia deixar de acrescentar que o PET incentivou-me muito a não contentar com a mesmice das coisas, mas a buscar sempre mais, a pensar grande e a ter muita coragem nessa busca. Com certeza minha visão de mundo não é mais a mesma."

"Tenho uma experiência mínima, mas se a primeira impressão for a que ficar, considero-me satisfeita. O programa está preenchendo as minhas expectativas, estou vivenciando momentos diferentes que até então não pensava em incorporar à minha vida. Estou dispondo de um tempo menor ao que eu tinha para estudar e neste novo tempo estou conseguindo reorganizar meu horário e adaptá-lo na prática. Estou crescendo interiormente e intelectualmente por assimilar com um indice maior de freqüencia e quantidade uma maior gama de conhecimentos. Sinto em meu interior uma necessidade em adquirir mais audácia e vencer $o$ medo de falar e expor minhas idéias e críticas.

"O que me levou a participar do processo seletivo de novos alunos do PET foi a vontade e o interesse em iniciar um trabalho científico, embora não soubesse concretamente como realizá-lo. Havia muitas dúvidas sobre como realizar um trabalho e até como conceituá-lo. Entretanto, durante as reuniões com a orientadora e com a tutora e demais integrantes do programa, obtive respostas a todas minhas dúvidas. Sobre a minha vivência em ser um bolsista PET posso dizer que estou ganhando um aumento de conhecimentos sobre vários assuntos. E o que para mim é mais expressivo: estou conseguindo desenvolver o meu lado crítico em leituras, debates, o que inclusive está me ajudando em outras disciplinas do curso de graduação. Gosto do incentivo do programa em participar de eventos culturais e cientificos, uma maneira de enriquecer-mos como pessoa e como universitário. Minha expectativa é de conseguir melhorar cada vez mais na realização de meus futuros trabalhos, de aprender cada vez mais, além de poder enriquecer meu curriculo com os eventos que participo com o apoio do programa."

Recentemente, o grupo foi submetido a uma avaliação formal pela CAPES e recebeu o conceito MUITO BOM, que é o conceito máximo atribuído a grupos PET e foi sugerido que o grupo trabalhe ativamente para maior interação com o corpo docente, mostrando-lhe o real sentido do PET.

\section{CONSIDERAÇÕES FINAIS}

A maioria dos alunos procura o Programa Especial de Treinamento (PET) por acreditar que se trata de um Programa de Iniciação Científica, com uma bolsa destinada ao aluno para desenvolver projetos e/ou investigações, haja visto o "clima de pesquisa" que há na unidade universitária e que o aluno percebe desde o seu ingresso.

No decorrer das atividades, se depara com um programa que visa além de desenvolver o espírito científico, investir em um aluno "com potencial" estimulando sua criatividade, relacionamento grupal, conhecimentos gerais e específicos, cultura, conhecimentos de língua estrangeira, política, etc.

Desta forma, o perfil desejado do bolsista é de um indivíduo que tenha bom relacionamento com colegas e professores, seja criativo, disponível, e interessado em trabalhar em grupos e em horários extraordinários, curioso, questionador, motivado para o estudo e a iniciação científica e que tenha iniciativa, capacidade de liderança, maturidade e que seja dinâmico.

O grupo tem claramente definido no momento da seleção, o perfil desejado do bolsista admitindo-se uma pessoa que complete o que o grupo necessita e que some ao conjunto o que é necessário e não apenas dentro de uma perspectiva individual de qualificação pessoal sem a visão do todo.

Finalmente o PET é um meio pelo qual, o aluno pode obter conhecimentos por atividades que não são executadas somente em salas de aulas ou por meio de leituras.

Quanto às atividades de pesquisa, o programa serve como uma forma de iniciar o bolsista ao questionamento crítico e o desenvolvimento do espírito científico. HARRISON et al. (1991) indicam que os 
alunos não retém conhecimentos suficientes sobre a pesquisa somente através de métodos tradicionais. A realização de suas investigações iniciais, divulgação destas em eventos científicos e uma relação estreita com um orientador são formas de instalar uma atitude positiva e uma auto-confiança nestes alunos que têm o privilégio de poderem desfrutar deste programa na graduação.

Sem dúvida, há um investimento em alunos com potenciais e que reverterá em benefícios para a profissão e conseqüentemente para a população em geral, através da prestação de cuidados de qualidade. Esta é a finalidade do alto investimento nestes estudantes.

\section{THE EXPERIENCE OF THE SPECIAL TRAINING PROGRAM INTHE EDUCATION OF UNDERGRADUATE NURSING STUDENTS}

This study presents the experience of the Special Training Program of the University os São Paulo at Ribeirão Preto College of Nursing - Brazil, since 1989. It is a program, directed to a group of twelve undergraduate students who show potential, habilities and interest. It provides under the orientation of a tutor-professor, the conditions to perform extra-curriculum activities, and develop scientific studies. The activities carried out by this group of students are: a course of foreign language, weekly meetings with the tutor, scientific investigation under the orientation of a teacher and discussion of scientific themes. These students act like of multiplication agent, disseminating ideas and practices borrowed from other students. The program has an excellent reputation in the brazilian academic area, and some of the ex-students are attending graduate programs, and according to its participants, it provides a personal and professional growth, through promoting activities that lead to the integration of the academic formation and the future professional activity.

KEY WORDS: nursing students, research in undergraduate courses

\section{LA EXPERIÊNCIA DEL PROGRAMA ESPECIAL DE ENTRENAMIENTO EN LA EDUCACIÓN DE ESTUDIANTES DE PREGRADO EN ENFERMERÍA}

Este estudio presenta el Programa Especial de Entrenamiento (PET) financiado por la Coordinación de Perfeccionamiento de Personal de Enseñanza Superior (CAPES), en funcionamiento desde 1989, en la Escuela de Enfermería de Ribeirão PretoUSP y destinado a un grupo de doce (12) estudiantes con potencial, habilidades e interés en investigación. El programa propicia la orientación de un tutor, condiciones para adelantar actividades extracurriculares y desarrollo de estudios relacionados al pregrado. La actividades relacionadas son: curso de lingua extrangera, reuniones semanales, trabajo científicos con orientación de un profesor, discusión de temas científicos y participación en eventos. Los estudiantes actúan como multiplicadores dimensinando ideas y prácticas a otros estudiantes. El PET tiene excelente concepto en el área académica y algunos exalumnos están involucrados en programas de post-grado. Según los becanos, el programa contribuye para su crecimiento personal y profesional a través de la promoción de actividades que llevan a la investigación académica y de la futura actividad profesional.

TÉRMINOS CLAVES: alumnos de pregrado, iniciación cientifica

\section{REFERÊNCIAS BIBLIOGRÁFICAS}

01. AMADOR, M.; BRITTO, J.E.F.; VALIDO, S.; PENÃ, M. El trabajo científico de los estudiantes: su papel en la formación de los professionales de la salud. Educ. Méd. y Salud, v. 18, n. 4, p. 344357, 1984.

02. ANGERAMI, E.L.S.; GOMES, D.L.S.; MISHIMA, S.M.; HAYASHIDA, M.; RIBEIRO, C.M.M.; REIS J.N. Disciplinas ministradas nos cursos de enfermagem da região sudestecaracterização da situação existente. Ribeirão Preto, 1994. 19 p. (mimeografado).

03. ASHTON, H.; SHULDHAN, C. An exploratory study of students' perceptions of the benefits of regular small group tutorials in a 2-year day release course. J. Adv. Nurs., v. 20, p. 925-934, 1994.
04. BRASIL. Ministério da Educação e do Desporto. Portaria n 1721, 15/12/1994. Brasília, 1994.

05. BURKHALTER, P.K.; KIM, H.T. The honors program approach to undergraduate research in nursing. J. Nurs. Staff, v. 15, n. 5, p. 21-25, jan. 1976.

06. DESSEN, M.A. O programa especial de treinamento - PET: evolução e perspectivas futuras, 1995. (mimeografado).

07. HARRISON, L.L.; LOWERY, B.; BAILEY, P. Changes in nursing students' konowledge about and attitudes toward research follewing an undergraduate research course. J. Adv. Nurs., v. 16, p. 807-812, 1991. 